\title{
Possibility of Improvement in Game Animal Utilization
}

\author{
Yukichika Kawata
}

\begin{abstract}
Although we are surrounded by many natural products, we tend to utilize lesser amounts of these resources with increasing economic development, thus shifting our consumption towards artificial resources such as farm animals. The purpose of this paper is to re-evaluate the shift in the use of natural resources and associated issues, using the Japanese sika deer as an example. Japan's high economic growth has improved both the amount of food supply and its quality, but it has also resulted in a decrease in deer meat consumption. The recent aging of and decrease in the number of residents in rural (mountainous) areas have led to an increase in the population levels of wild ungulates, resulting in increased degradation of agricultural and forestry resources, car and train accidents, and damage to vegetation cover. We conducted two surveys. First, we used a nationwide survey to assess the current status of deer meat consumption. Second, we provided detailed information about the effects of the current level of deer meat consumption, including the negative aspects of the increasing deer population and deer meat utilization. We found that appropriate and sufficient information may change attitudes toward deer meat and may increase its consumption such that supply and demand are balanced.
\end{abstract}

Keywords-Cervus nippon, game meat, consumption, nationwide survey, classroom experiment.

\section{INTRODUCTION}

$\mathrm{W}$ ILD meats have been used as a staple food worldwide since ancient times. In some countries, wild meats are referred to as bush meats and/or seasonal game meats, and they are much sought after because they possess desirable properties such as wholesomeness and leanness.[1] Hunting of game animals and utilization of their meats can be interpreted as human disturbance of nature.[2] Therefore, it is desirable to maintain a stable relationship between humans and the surrounding nature while hunting. It is often the case that too much hunting pressure reduces the game animal population. However, recently, lesser hunting pressure combined with the absence of predators has resulted in the increase of the game animal population, which in turn causes severe ecosystem degradation.[3] Hunting pressure has decreased substantially over time in Japan. One of the most notable decreases was observed during the reign of Tokugawa Tsunayoshi, the fifth Shogun of the Tokugawa government. Since 1687, a series of government proclamations, often referred to as the Law Prohibiting Cruelty to Animals, were issued. Under this

Yukichika Kawata is with Faculty of Economics, Kindai University, 4-1 Kowakae 3-chome, Higashiosaka, Osaka 577-8502, Japan. law/series of proclamations, people were prohibited to kill living creatures, including humans, domestic animals and wildlife. More recently, it has been reported that an increasing number of wild boars have begun roaming certain areas that were abandoned by local residents after the Great East Japan Earthquake on account of the resulting radioactive contamination.[4,5] Although the reasons behind such increases in the game animal population differ across cases, they share a common cause, namely, human interference.

In addition to the above examples, currently, it is commonly observed that hunting pressure for game animals has decreased in many local areas of Japan. This has increased the extent of bush cover for wild animals, which makes it easier for them to access agricultural lands and cause damage.[6] This leads to a negative cycle of farm retirement and increasing wild animal populations.

Therefore, it is important to restrain the population size of wild animals to below a certain limit by increasing hunting pressure. One of the most promising solutions is the increased utilization of carcasses, namely, as game meat. The first purpose of this paper, therefore, is to determine demand of the average Japanese for game meats. Naturally, decrease in this demand has reduced hunting pressure for game animals in present-day Japan. Thus, the second purpose of this paper is to examine if improved information provision about the current status of game animals and issues caused by these animals under reduced hunting pressure may improve utilization of game meats of hunted animals. In what follows, we limit our investigation to Japanese sika deer, which has wrought substantial damage on the ecosystem and human society in recent times.

\section{CuRREnt Status OF Hunting AND Ungulate Numbers IN JAPAN}

\section{A. Current status of hunting in Japan}

Hunting can be classified into subsistence hunting, commercial hunting and sport hunting.[7,8] When considering the high portion of control kills for alleviating varied damages caused by increasing populations of game animals, it would be appropriate to include control kills in the Japanese context.[9] There is almost no subsistence hunting in present-day Japan. Commercial hunting exists in Japan, but the markets for carcasses are normally limited. Sport hunting is a more favoured style of hunting, but the number of sport hunters is 
limited. Control killing is the most typical hunting activity in Japan, where hunters are often paid depending on their participation in control kills and the number of control kills.

Figures 1 distinguishes the number of sika deer hunted in Japan between 1960 and 2012 from other heads. We see that while the hunted numbers include animals from commercial hunting and sport hunting, they mainly comprise control kills. 'Others' includes both control kills and hunting as defined by the Specified Wildlife Conservation and Management Plan. Figure 2 shows the number of hunting license holders between 1975 and 2012 at 5-year intervals. Those who were older than 60 years comprised $8.9 \%$ of the total in 1975 , but this percentage has increased to $65 \%$ in 2012 . Therefore, we see rapid aging among hunters in recent years. Simultaneously, the number of hunters has decreased: 518 thousand hunters in 1975 dwindled to around less than half the number, 200 thousand, after the year 2000 .

\section{B. Damages caused by the increasing wildlife population}

Figures 3 shows both estimated monetary damages and the extent of damage caused by sika deer and wild boars between 1960 and 2012 throughout Japan. The estimated monetary damages caused by both animals are almost the same, as shown in Figure 3. On the other hand, the extent of estimated damage caused by sika deer exceeds that caused by wild boars by 5 to 10 times ( 10 times on average). This result may imply that the omnivorous wild boar damages agricultural products of higher economic value compared to the herbivorous sika deer. According to official data [12], the estimated monetary damages caused by sika deer and wild boars account for nearly 75\% (on average, between 1999 and 2013, and the same applies hereinafter) of the total damage caused by wild animals and birds, and $82 \%$ of the total damage caused by wild animals alone. Similarly, the extent of estimated damages caused by the deer and wild boars accounts for nearly $40 \%$ and 52\% of the total damage caused by wild animals and birds and that caused by wild animals alone, respectively. As suggested above, most of the economic damage caused by wild animals could be attributed to the sika deer and wild boars.

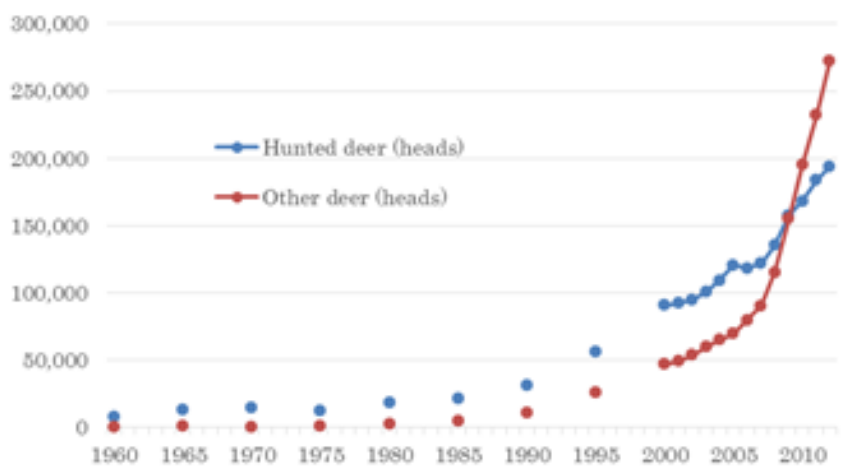

Fig. 1: Number of sika deer hunted $(1960$ - 2012)[10]

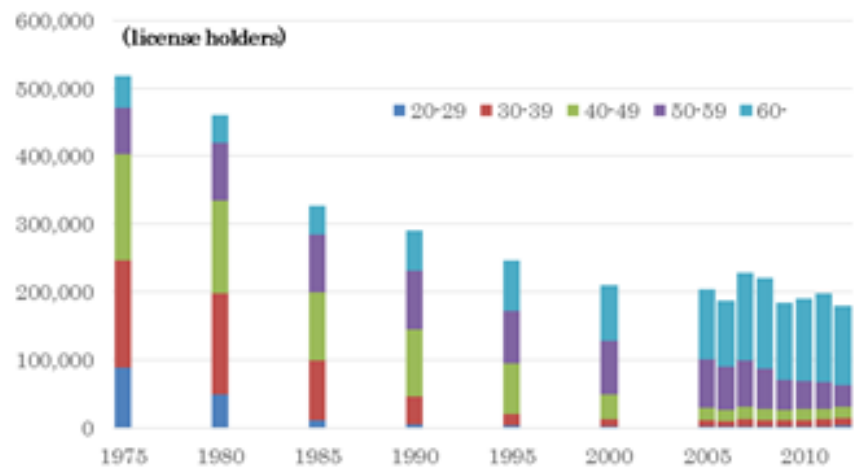

Fig. 2: Number of hunting license holders (1975 - 2012)[11]

Unfortunately, comprehensive national statistics for damages other than those to agriculture and forestry caused by wild animals do not exist. However, many such incidents have occurred throughout Japan and are reported on a daily basis. These include traffic accidents (e.g. collision of a car with sika deer), train accidents (e.g. collision of a train with sika deer or delayed trains due to sika deer crossing the railway track), damage to vegetation (e.g. overgrazing of vegetation excluding repellent plants by sika deer, leading to loss of biodiversity and mudslides), damage to the property of rural/urban residents (e.g. appearance of sika deer and wild boars in urban areas, their intrusion into shops and/or school buildings and disturbance to daily life).

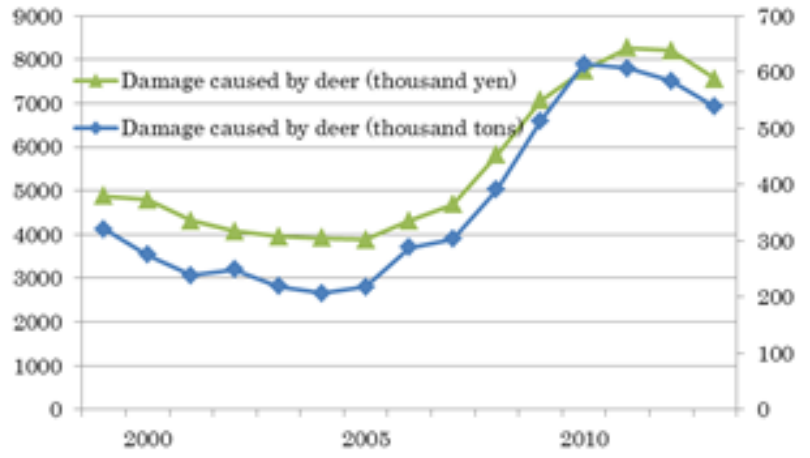

Fig. 3: Estimated monetary / extent of damage (1999 - 2013) [12]

\section{EMPIRICAL EXPERIMENT}

\section{A. Subjects and aim of the experiment}

We conducted pre- and main surveys from 25-26 February 2014 and 14-15 March 2014, respectively, through a professional web research company. There were 96 and 888 subjects in the pre- and main surveys, respectively. In this paper, we used the data obtained from the main survey.

We applied price sensitivity measurement (PSM) analysis, which was first used by [13] in his seminal paper. We conducted 3 PSM analyses by dividing the data on the basis of the following three criteria: Criterion 1 (external circumstances): Existence of a hygiene control guideline for wild meat in the subject's prefecture; Criterion 2 (personal experiment): Subject's experience of sika deer meat consumption; Criterion 3 (personal knowledge): Subject's knowledge concerning damages caused by sika deer. 


\section{B. Price Sensitivity Measurement (PSM) analysis}

The four questions and their corresponding explanations of the PSM survey are as follows.

\section{Please read following descriptions.}

Deer meat, which is called gibier in some European countries, is used as the primary ingredient for certain special/exquisite meals. The meat of the Japanese sika deer is regarded as one of the most delicious of all cervids. Because deer meat is lean (contains little fat), its taste is unfamiliar to most Japanese. However, deer meat started gaining popularity among the Japanese because it is healthier than other existing meats, as it contains fewer calories, more protein and more iron and vitamin $B$, which reduce the risk of adult diseases. Before distribution through markets, deer meat hunted in Japan is processed according to the Food Hygiene Law of Japan.

The current approximate prices for deer meat are as follows:

\begin{tabular}{|l|l|}
\hline Wild deer meat, hunted & $\begin{array}{l}10 \% \text { lower than typical } \\
\text { Japanese beef }\end{array}$ \\
\hline $\begin{array}{l}\text { Half-cultivated deer meat (note } \\
1)\end{array}$ & $\begin{array}{l}\text { Nearly the same price as } \\
\text { typical Japanese beef }\end{array}$ \\
\hline
\end{tabular}

Note 1: Half-cultivated deer refers to captured wild deer, which is raised and fattened for nearly half a year with feedstuff in order to improve its taste and texture, so that they appear similar to those of domestic meats.

\section{Question}

What are your thoughts about the price of wild [half-cultivated] deer meat (leg or loin)? Please answer the following four questions.

$[\mathrm{QH}]$ At what price would you consider $100 \mathrm{~g}$ of this deer meat to be expensive?

[QL] At what price would you consider $100 \mathrm{~g}$ of this deer meat to be a bargain?

[QTH] At what price would you consider $100 \mathrm{~g}$ of this deer meat to be too expensive?

[QTL] At what price would you consider $100 \mathrm{~g}$ of this deer meat to be too cheap, and would you have doubts about the quality of the product at this price?

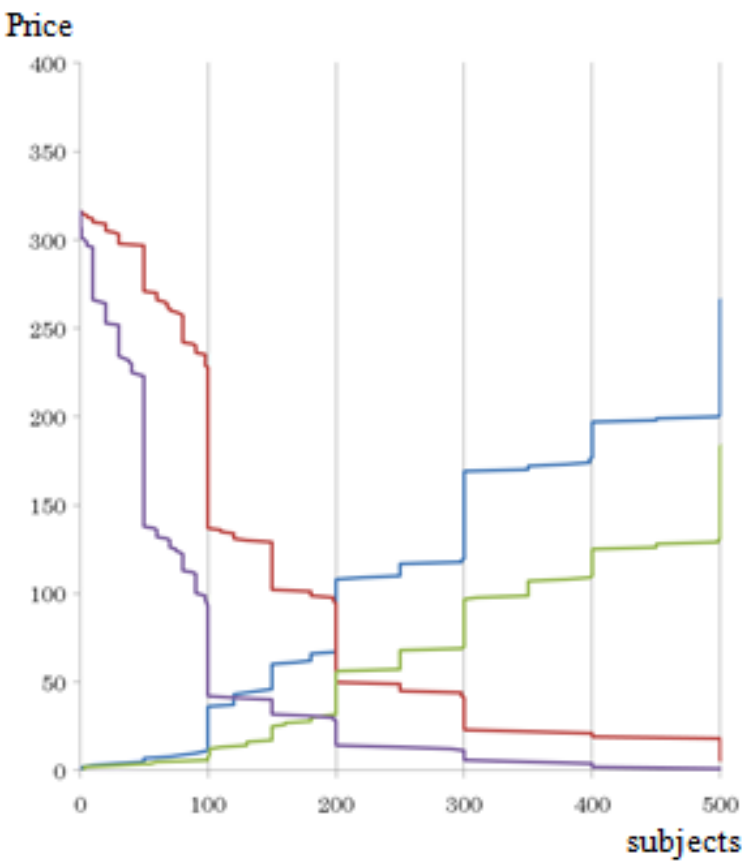

Fig. 4 PSM analysis for formulated prefectures

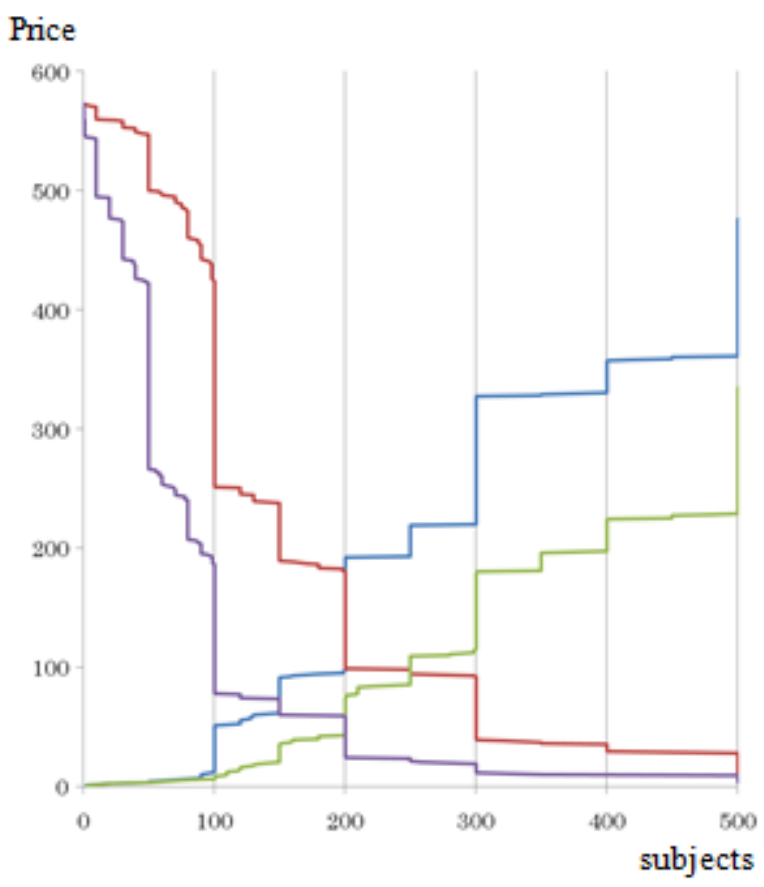

Fig. 5 PSM analysis for unformulated prefectures

Four curves were drawn depending on the subjects' answers: expensive, cheap, too expensive and too cheap (for answers to QH, QL, QTH and QTL, respectively). Then, we calculated the Indifference Price Point (IPP), Optimal Price Point (OPP), Point of Marginal Cheapness (PMC) and Point of Marginal Expensiveness (PME) as the intersections of the expensive and cheap curves, too expensive and too cheap curves, expensive and too cheap curves, and too expensive and cheap curves, respectively.

For analysis 1, we divided the samples of the main survey into two groups: those who live in a prefecture where a hygiene control guideline for wild meat exists (hereafter, 
'formulated prefectures') and those who live in a prefecture where such a guideline does not exist (hereafter, 'unformulated prefectures'). We applied the PSM analysis to these two samples and compared the results (Figures 4 and 5). We also conducted analyses 2 and 3 in a similar manner.

Table 1 summarizes the results of analyses $1-3$. We observe a marked difference for the results of analysis 3 , where evaluations for the PMC, OPP, IPP and PME by subjects without the aforementioned knowledge are substantially lower than those for subjects with it. This result implies that if we were to improve subjects' knowledge about the damages caused by the increased population of game animals, their evaluations for PMC, OPP, IPP and PME may increase considerably, thus resulting in increased game meat consumption.

\section{Estimation of current demand}

We also asked the following question.

\section{Please read following description.}

Currently, hunters shoot deer for sport hunting and consume some portion of the carcasses in their homes. However, the number of such hunters has been decreasing yearly, and most of these hunters are very old today. Moreover, the hunting technique differs substantially from one hunter to another, resulting in poor hunting performance.

Therefore, recently, some local governments have started examining the possibility of fostering professional deer hunters for continuous and efficient deer culls, in order to control the deer population. We must utilize hunted wild deer to support this decision and provide professional deer hunters a living.

\section{Question}

Suppose that there is almost no sport hunting and consumption of game meats is limited in your local government. Therefore, professional deer hunters would be required to control the deer population through hunting. In such a case, how much deer meat (leg or loin) will you consume per year, assuming it is sold at a price of $n$ yen/100 $\mathrm{g}$ ? If you refuse to buy the meat nonetheless, answer ' $0 \mathrm{~g}$ '.

\section{( ) $g$}

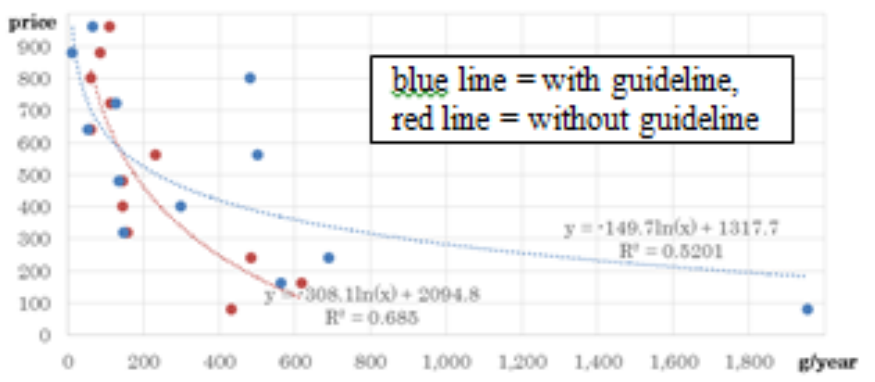

Fig. 6: Demand curves for deer meat (with and without guideline)

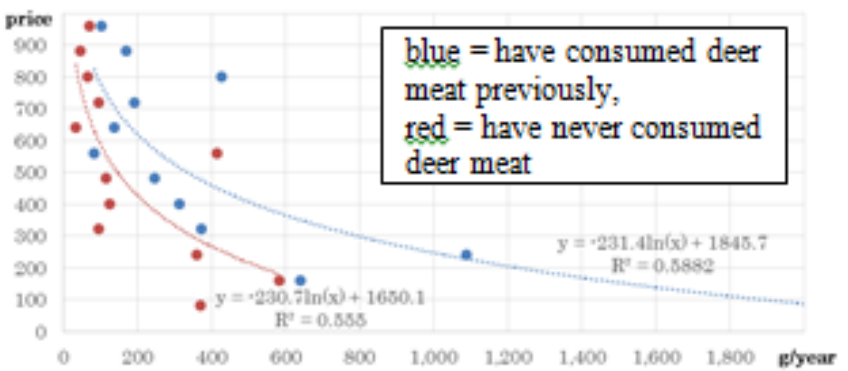

Fig. 7: Demand curves for deer meat (with and without past consumption)

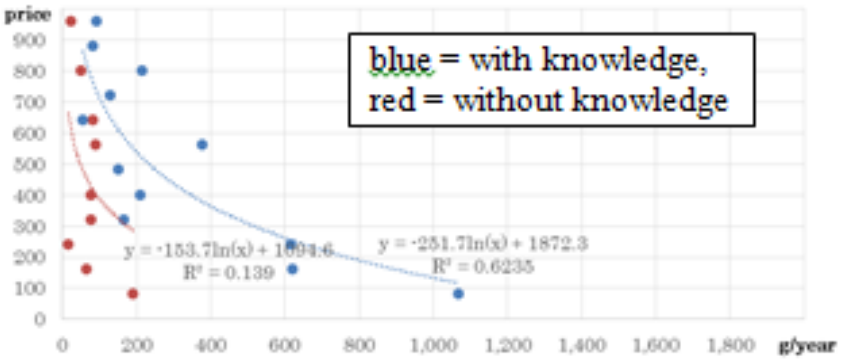

Fig. 8: Demand curves for deer meat (with and without knowledge of damages)

TABLE I: Results of the PSM analyses (yen)

\begin{tabular}{lllllll}
\hline \multirow{2}{*}{ Analysis } & & PM & OPP & IPP & PM & N \\
& & $\mathrm{C}$ & & & $\mathrm{E}$ & \\
\hline 1 & yes & 120 & 185 & 200 & 200 & 572 \\
(guideline) & no & 150 & 200 & 200 & 250 & 316 \\
\hline 2 & yes & 138 & 189 & 200 & 250 & 239 \\
(experience) & no & 150 & 200 & 200 & 250 & 649 \\
\hline 3 & yes & 150 & 200 & 200 & 250 & 785 \\
(knowledge) & no & 100 & 109 & 150 & 200 & 103 \\
\hline
\end{tabular}

Note: Q1, Q2 and Q3 refer to questions regarding 'external circumstance', 'personal experiment' and 'personal knowledge', respectively.

In this question, we randomly set $\mathrm{n}$ yen as $80,160,240$, $320,400,480,560,640,720,800,880$ or 960 . The results of analyses $1-3$ are shown in Figures $6-8$. The results show that if a subject lives in a formulated prefecture, or has experience of sika deer meat consumption, or has knowledge concerning damages caused by sika deer, he/she tends to have higher demand.

\section{ClassRoom EXPERIMENT}

\section{A. Subjects and aim of the examination}

We provided the questionnaire to a university classroom during a lecture. The university is located in Hokkaido, Japan, and we explained the current situation with respect to game animals, their impacts, the need for a solution and so on. We hoped that such an analysis would reveal if the provision of adequate information may stimulate demand for game meat and improve game animal utilization beyond present-day levels.

The subjects were students at the Agriculture and Economics class, one of the relay-type lectures conducted by the author at his former university. Of the total of 207 students, 192 attended the author's class and responded to all the 
questions in the required manner. The lecture and experiment took place on 2 August 2013. Because this university is located in Hokkaido, we selected the Hokkaido sika deer, which is one of the subspecies of the Japanese sika deer, as the object of the survey.

\section{B. Background data}

We provided detailed information about the Hokkaido sika deer to the subjects. In 2011, 13.7 thousand of Hokkaido sika deer were hunted, while their estimated population size was 640 thousand.[14] Given that the estimated population size in 2010 was 650 thousand, the extent of hunting in 2011 was so low that it almost maintained the population size recorded in 2010. As a rule of thumb, we rounded off the numbers in the questions, such that the sustainable population size and number of deer that could be hunted sustainably were 600 thousand and 100 thousand, respectively.

We then calculated per capita consumption required for the sustainable utilization of the Hokkaido sika deer. Suppose we hunt 100 thousand heads of Hokkaido sika deer annually and utilize its carcasses to the extent possible within Hokkaido. Then, the per capita deer consumption for a Hokkaido citizen is $218 \mathrm{~g} / \mathrm{year}$. This figure was calculated under some assumptions.

1) We supposed that 80 thousand heads of sika deer is a suitable number for consumption. (Some portion (we supposed 20 thousand heads) of the hunted Hokkaido sika deer would not be suitable as game meat, assuming this portion of animals is sick, too old to consume, and/or damaged during hunting (e.g. internal organs may be damaged). Similarly, there may be some difficulty in carrying the carcasses from the hunting ground to a slaughtering centre or the carcasses may be lost after the hunt.)

2) We supposed the fresh meat weighs $25 \mathrm{~kg}$ per head. (Assuming the weight of the Hokkaido sika deer to be 80 $\mathrm{kg}$ and its yield rate as $35 \%$, we arrived at the same value (25 kg). Of this $25 \mathrm{~kg}$, the leg and loin account for around $10 \mathrm{~kg}$ and $2.3 \mathrm{~kg}$, respectively.)

3) Because some portion of the Hokkaido sika deer carcass may have already been utilized, we supposed that $50 \%$ of

Hunted sika deer may be utilized sustainably provided all Hokkaido citizens consume $218 \mathrm{~g}$ of the sika deer meat annually. How much sika deer meat do you believe you can consume annually? Provide your reply after reading the following information.

[Note 1]

\begin{tabular}{|l|l|l|l|}
\hline Meal/year & Never $(0 \mathrm{~g})$ & Once $(109 \mathrm{~g})$ & Twice $(218 \mathrm{~g})$ \\
\hline Applicable tax & 437 yen & Reduces to 327 yen & Reduces to 218 yen \\
\hline
\end{tabular}

[Note 2] Extent by which you would need to reduce the other (non-deer) meat you consume in order to spend the same amount of money you currently pay for meat

\begin{tabular}{|l|l|l|l|}
\hline Meal/year & Never $(0 \mathrm{~g})$ & Once $(109 \mathrm{~g})$ & Twice $(218 \mathrm{~g})$ \\
\hline Beef, 15 meals & 15 meals & 14 meals $(-1$ meal $)$ & 13 meals $(-2$ meals $)$ \\
\hline Pork, 40 meals & 40 meals & 37 meals $(-3$ meals $)$ & 34 meals $(-6$ meals $)$ \\
\hline Chicken, 30 meals & 30 meals & 26 meals $(-4$ meals $)$ & 22 meals $(-8$ meals $)$ \\
\hline
\end{tabular}

Sika meat [ ] time(s)/year

*You need not necessarily reply in whole numbers (e.g. 0.5 times/year may be a valid answer)

For the calculations in Note 2, we used the following data: annual per capita consumption of beef and pork were $2234 \mathrm{~g}$ (6119 yen) and $6044 \mathrm{~g}$ (7826 yen), respectively.[15] the carcass is left to us. (The sale of deer meat differs according to the part: the leg and loin sell well while many other parts do not appeal to humans. It is more realistic to suppose that such parts will be utilized as material for dog food utilized instead. In addition, some portion of the 100 thousand heads may have already been canned or processed as souvenirs and other items. Therefore, we supposed that $50 \%$ of the carcass will be processed as meat for human consumption.)

Using the above three assumptions, the total amount of Hokkaido sika deer meat destined for human consumption was calculated as 80 thousand heads/year $\times 25 \mathrm{~kg} / \mathrm{head} \times 50 \%=$ 1000 ton/year. The population size (greater than 20 years old) of Hokkaido is 4582 thousand. Therefore, per capita consumption necessary for utilization was calculated as [1000 ton/year] $/ 4582$ thousand $=218 \mathrm{~g} /$ year.

\section{Scenario for subjects}

We provided subjects with information about the increase in the population size of the Hokkaido sika deer and associated damages. We explained the processing cost as follows. If hunted sika deer are to be utilized and buried at a hunting ground, the total cost is assumed to be 20 thousand yen/head (hunting cost of 10 thousand yen + processing cost (burying carcasses) of 10 thousand yen). If the meat of the hunted sika deer is destined for consumption, the total cost is assumed to be 10 thousand yen/head (hunting cost of 10 thousand yen + meat processing cost of 10 thousand yen + revenue of 10 en selling the meat).

If the number of deer hunted is 100 thousand heads/year, it would cost Hokkaido 2 billion yen $(=100$ thousand heads $\times 20$ thousand yen/head). Because there are 4582 thousand Hokkaido citizens greater than 20 years of age, it follows that each Hokkaido citizen would need to pay a tax of 437 yen $(=2$ billion yen/4582 thousand). If they utilize $50 \%$ of the carcasses, they would need to pay an annual tax of 218 yen.

Suppose a subject consumes about $109 \mathrm{~g}$ of sika deer meat per meal. We asked the following questions in this regard. 


\section{D.Results}

Figure 9 shows the results for the above-mentioned questions. As explained before, if each Hokkaido citizen consumes $218 \mathrm{~g}$ of sika deer meat (corresponding to two meals) annually, half the current carcasses will be utilized. The results show that subjects may consume 3.28 meals annually on average (median $=2$ meals/year), which implies that the utilization level of hunted sika deer meat targeted in this research (218 g/year/person) will be satisfied. Seventy-three subjects (38\% and the largest proportion) replied 'twice'.

Finally, we examine the answers to the free-answer questions. Forty-seven subjects stated that there had 'no experience of sika deer meat consumption and related issues', and 18 subjects mentioned that they had a 'negative image toward sika deer meat in terms of its smell and toughness'. While the other subjects raised different issues/concerns, they all made up only a very small proportion of the total, and thus, they need not be included here. Twenty-seven subjects proposed that the current situation could be improved by 'making sika deer meat a local specialty', 25 subjects proposed 'conveying the positive aspects of consuming sika deer meat to citizens', while 18 subjects suggested 'providing opportunities to consume sika deer meat' may help matters. All the abovementioned proposals have already been implemented in some way. In addition to these and other efforts, 18 subjects suggested 'providing more information to Hokkaido citizens', which is essentially the same idea proposed in this paper. Moreover, 13 subjects suggested 'selling sika deer meat at ordinary shops, because currently, sika deer meat is sold only at specific shops that are less accessible to typical citizens'. Nine subjects mentioned the 'possibility of reducing the price of sika deer meat until more citizens experience consuming it'. These ideas are relatively new and have promise.

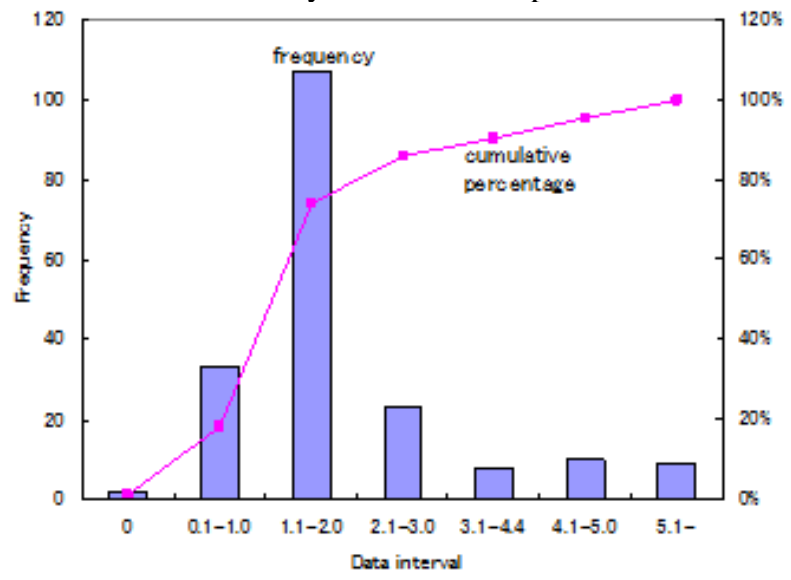

Fig. 9: Subjects' answers regarding the hypothetical consumption of sika deer meat

\section{DISCUSSION}

In section 3, we divided the samples into two groups based on three criteria: external circumstance, personal experiment and personal knowledge. Among these three criteria, the last criterion is the easiest to change through political intervention while the first and the second criteria tend to reflect the prevailing public situation. Fortunately, our results show that the prices of sika deer meat evaluated on the basis of the PSM analysis are most influenced by the last criterion (personal knowledge). On the other hand, analyses for the first and second groups showed that the OPPs for formulated prefectures and when the subject has had experience of deer meat consumption are low, at 185 yen and 189 yen, respectively. These results suggest that such subjects place less value on sika deer meat. Current real prices for Hokkaido sika deer meat are 622, 591, 386 and 370 yen for tenderloin, loin, chuck and leg, respectively.[16] Compared with our results, the actual price range is relatively higher. Thus, one of the reasons for the poor sale of sika deer meat could be its relatively high price compared with the subjects' evaluations.

In section 4 , we examined if information provision about the current status of Hokkaido sika deer and associated damages would increase consumption of sika deer meat. The result of the classroom experiment shows that there is a possibility that our targeted level of utilization (218 g) may be realized. Notably, we conducted this experiment in Hokkaido, which has one of the most advanced local governments in Japan, because the prefecture has experienced the most serious damage in this context, and many attempts have already been made to improve deer meat utilization here. It remains to be seen whether our results from the classroom experiment are applicable to other areas of Japan.

\section{REFERENCES}

[1] L. C. Hoffman, and E. Wiklund, "Game and Venison - Meat for the Modern Consumer,” Meat Science, 74(1), pp. 197-208, 2006. http://dx.doi.org/10.1016/j.meatsci.2006.04.005

[2] P. Marchand, M. Garel, G. Bourgoin, D. Dubray, D. Maillard, and A. Loison, "Impacts of Tourism and Hunting on a Large Herbivore's Spatio-temporal Behavior in and around a French Protected Area," Biological Conservation, 177, pp. 1-11, 2014. http://dx.doi.org/10.1016/j.biocon.2014.05.022

[3] W. Stolzenburg, Where the Wild Things Were. USA: Bloomsbury, 2008.

[4] The Japan Agricultural News, "Refrigerators are filled with hunted wild boars: Soma city, Fukushima," February 5, 2015.

[5] Fukushima-Minpo News, "Number of hunted wild boar to be increased in Fukushima," February 7, 2015.

[6] Ministry of the Environment, "The National Biodiversity Strategy of Japan 2012 - 2020," 2014.

[7] Ph. Chardonnet, B. des Clers, J. Fischer, R. Gerhold, F. Jori, and F. Lamarque, "The value of Wildlife," Revue Scientifique et Technique Off. Int. Épiz., 21(1), 15-51, 2002.

[8] A. J.Loveridge, J. C. Reynolds, and E. J. Milner-Gulland, "Does sport hunting benefit conservation?," in Key Topics in Conservation Biology, D. Macdonald, and K. Service, Ed. Blackwell, Malden, 2006, pp. 222238.

[9] Y. Kawata, "Problems of underutilization of natural capital: With a focus on renewable natural capital in Japan," in Conservation and Evaluation of Natural Capital, K. Asano, and M. Takada, Ed. Minerva Publishing Co. Ltd., Tokyo, 2009, pp. 11- 28.

[10] Ministry of the Environment. (2015). Number of wild animals and birds - hunted and others. Available: http://www.env.go.jp/nature/choju/docs/docs4/higai.pdf

[11] Ministry of the Environment. (2015). Number of hunting license holders by ages. Available: http://www.env.go.jp/nature/choju/docs/docs4/menkyo.pdf

[12] Ministry of the Environment. (2015). Estimated damages caused by wild animals and birds to agricultural products. Available: http://www.maff.go.jp/j/seisan/tyozyu/higai/h_zyokyo2/h25/pdf/150123 _e.pdf 
[13] P. Van Westendorp, "NSS-Price Sensitivity Meter: A New Approach to Study Consumer Perception of Price," in Proceedings of the ESOMAR Congress, 1976.

[14] Hokkaido. (2015). Estimation of Hokkaido sika deer population size in fiscal 2013.2 Available: http://www.pref.hokkaido.lg.jp/ks/est/H25suiteiseisokusuu.pdf

[15] Agriculture \& Livestock Industries Corporation. (2015). Designated stabilized price for meat: Beef. Available: http://lin.alic.go.jp/alic/statis/dome/data2/nstatis.htm

[16] Hokkaido. (2011). Report on the Hokkaido sika deer utilization survey project. 